\title{
APUNTES SOBRE AMOR Y RISA
}

\author{
NOTES ON LOVE AND LAUGHTER
}

\section{DIETER OELKER*}

\section{RESUMEN}

La risa aparece en situaciones tan variadas, que resulta difícil encontrar para ella un denominador común. Consecuente con ello aparecen diversas concepciones de la risa que como celebración de la vida se relaciona íntimamente con el juego erótico y el placer sexual. El presente trabajo busca dar cuenta de esta relación, observada tanto en las culturas fundacionales de Occidente como en las culturas pre-hispánicas maya, quechua y azteca. En cumplimiento de tal propósito se anotan diversas acepciones de la risa advertidas en ambas áreas culturales. Para su mejor comprensión, se las sitúa ante el trasfondo de la gravedad que caracteriza a la cultura oficial vigente y desde la cual o en contra de surge la risa.

Palabras clave: Risa, placer, gravedad, incongruencia, resistencia, juego, libertad.

\begin{abstract}
Laughter emerges in so many different situations that it is difficult to find a common thread to it. Similarly, different conceptions of laughter arise that, as a celebration of life, is intimately related to erotic play and sexual pleasure. This paper attempts to account for this relation, observed both in the western founding cultures and in the Mayan, Quechua, and Aztec Pre-Hispanic cultures. For such purpose, various meanings of laughter observed in the two cultural areas are noted. In order to better understand
\end{abstract} udec.cl

* Profesor Emérito de la Universidad de Concepción. Concepción, Chile. Correo: doelker@ 
them, they are placed in the context of the gravity that characterises the present official culture and from which, or against which, laughter emerges.

Keywords: Laughter, pleasure, gravity, incongruence, resistance, play, freedom.

Recibido: 09.03.17. Aceptado: 18.06.17.

La risa loca no es únicamente una respuesta al principio del placer ni tampoco su copia o reproducción: es la sublimación, es la metáfora del placer.

Octavio Paz, Conjunciones y disyunciones.

$\mathrm{N}$ UESTRA CULTURA se halla atravesada desde sus orígenes por la gravedad y la risa. Ambas manifestaciones aparecen en los respectivos relatos fundacionales griegos y mesoamericanos, no obstante su diferente significación existencial. Igualmente, un tipo de risa se asocia en estas culturas y también en la hebraica desde sus comienzos con la pasión amorosa.

De hecho la risa aparece asociada al juego erótico, por ejemplo, cuando "Isaak se ríe [sakhaq, 'retozar', 'entregarse a juegos amorosos' (Soggin, 1997, p. 349)] con su mujer Rebeca”, en la Biblia Hebraica (Génesis 26, p. 8), o cuando en un poema náhuatl, la joven le dice a su amado: "Habremos de reír, nos alegraremos, habrá deleite” (León-Portilla, 1978, p. 186). Homero (1959) caracteriza a la diosa del amor, Afrodita, como la diosa "amante de la risa" (Ilíada, III, p. 424), y en un poema maya leemos:

todas las mujeres mozas,

[tienen en] pura risa

y risa

sus rostros (...), porque saben

que es porque darán

su virginidad femenil

a quienes ellas aman

(De la Garza, 1992, p. 363),

En unos versos quechuas se afirma que "al recordar esos tus ojos reidores quedo maravillado" (Bendezú Aybar, 1992, p. 16) y Pablo Neruda (1968: I, p. 945) alude metafóricamente a Afrodita $^{1}$ en su poema Tu risa cuando escribe:

\footnotetext{
${ }^{1}$ Remiten a la diosa griega de la belleza, el amor, el deseo y la pasión, las metáforas la rosa que es la flor de Afrodita, la espuma, porque la mitología griega se refiere a la diosa como la "surgida de la espuma", y en cuanto a la primavera leemos en Lucrecio, De rerum natura, v 738: "viene la primavera y Venus".
} 
Junto al mar en otoño,

tu risa debe alzar

su cascada de espuma,

y en primavera, amor,

quiero tu risa como

la flor que yo esperaba,

la flor azul, la rosa,

de mi patria sonora.

"El hombre es el único de los animales que ríe", escribe Aristóteles (2000b) en su tratado sobre las Partes de los animales (III: 10, 673a, pp. 8-9). Sin embargo, esta forma de expresión propia de los seres humanos es tan variada y múltiple, que necesariamente debemos preguntarnos por su origen, naturaleza y su función. La risa es un fenómeno cultural inestable que se transforma en el devenir histórico y varía de una comunidad a otra. Ella es, como destaca Bergson (1943, p. 15), una manifestación social, de manera que "para comprender la risa hay que reintegrarla a su medio natural que es la sociedad".

En una primera aproximación a la risa resulta apropiado distinguir entre aquella que surge como una manifestación afectiva y pasional de la alegría de vivir, y aquella otra de notación cerebral, que surge según Schopenhauer, en palabras de Borges (1996, IV, p. 330)2, ante "la paradojal e inesperada inclusión de un objeto a una categoría que le es ajena y a nuestra brusca percepción de esta incongruencia entre lo conceptual y lo real”. En consecuencia -y para señalar tan sólo algunos ejemplos-, quienes han reflexionado sobre esta relación y sus componentes han definido como fuente de la risa

-la "repentina transformación de una tensa expectación en nada" (Kant, 1966: $\$ 54,276)$.

-la colisión entre "lo rígido, lo hecho, lo mecánico por oposición a lo flexible, a lo vivo, a lo que está siempre cambiando" (Bergson, 1943, p. 99).

-"todo contraste entre el fondo y la forma, el fin y los medios, [...] contradicción ésta, por la cual la acción se destruye a sí misma y el fin se aniquila al realizarse". (Hegel 1970: III, p. 527).

${ }^{2}$ Véase también Schopenhauer, 1977: I, 1: \$13, p. 96. 
- "la remoción de una coerción interna" (Freud 1967, I, p. 910).

- "la percepción de una situación o idea en dos marcos de referencia

o contextos asociativos coherentes en sí mismos, pero incompatibles recíprocamente" (Koestler en Berger, 1998, p. 74).

Igualmente nos reímos cuando a través de un orden convencional excluyente se trasluce la realidad excluida (Ritter, 1974, p. 79), o al observar un sistema de normas ante el trasfondo de sus rupturas y desviaciones (Fietz 1995, p. 20). Así, por ejemplo, Nicanor Parra coloca en sus Artefactos visuales bajo un crucifijo vacío la leyenda "voy y vuelvo", de donde la risa que produce la evocación y trasluce de la realidad excluida -el solemne anuncio de la parusía ${ }^{3}$ - a través de un inesperado giro de carácter coloquial.

Desde los orígenes, la risa y el amor, la "risa loca que es la metáfora del placer", aparecen excluidos del espacio público y relegados al ámbito privado. Es así como Zeus le recuerda a Afrodita, "la diosa sonriente" (Ilíada, IV, p. 211), que "a ti no te han sido asignadas las acciones bélicas, antes por el contrario, ocúpate de los placenteros afanes del matrimonio, pues de aquellas otras ya se encargan el impetuoso Ares y Atenea" (Ilíada, V, pp. 428 ss.). Ellos, el amor y la risa, quedan marginados del mundo oficial regido por la autoridad de la fuerza y de la razón, lo cual le aporta a Occidente el fundamento mítico del triunfo de la gravedad.

No obstante, Aristófanes propone en su Lisístrata el principio: "Nada de fuerza [...]. Sensatez, discreción: eso es lo que se necesita” (1991, p. 215), como medio para solucionar los problemas públicos. El autor actualiza esta máxima cuando relaciona en el texto la razón con el amor y, pensando en Afrodita, con la risa y la pasión.

Se trata de poner fin a la guerra del Peloponeso para lo cual las mujeres se conjuran de no tener trato con sus maridos porque, como dice Lisistrata, "si el dulce Eros y Afrodita infiltran en nuestros senos y en nuestras caderas un atractivo ardor y ellos, sin sus caricias, andan con bastones duros por delante, segura estoy que nos han de llamar justamente los griegos: las que acaban con la guerra" (Aristófanes, 1991, p. 217). Las atenienses y espartanas se valen exitosamente de su poder: la risa y el amor, relegado al espacio privado e íntimo como medio para solucionar los problemas de la ciudad. Los mundos se invierten: “¿De modo que los problemas púbicos van a desenredarse como si fueran hilos de lana en husos?” (p. 218), pre-

\footnotetext{
${ }^{3}$ Véase, por ejemplo, en el Evangelio según Mateo 16: 27 del Nuevo Testamento, Biblia de Jerusalén.
} 
gunta escandalizado el Comandante de la Acrópolis -inversión de mundos que se despliega en una pluralidad de situaciones que causan hilaridad en el espectador. La alianza entre el amor y la risa y la razón se impone sobre la violencia guerrera, la unión entre Afrodita y Atenea es más poderosa que la relación entre Ares y Atenea, las fuerzas que prevalecen en el quehacer del estado y los gobiernos se subordinan a los poderes que actúan en la privacidad.

Sin embargo, Platón (1969) ratifica en sus escritos el triunfo de la gravedad porque, como afirma en el Filebo, 48c, "la risa es, en suma, un vicio" y sólo es necesario conocer lo risible para evitarlo, por cuanto constituye algo alejado de lo normal. "Es preciso", escribe en las Leyes, 817a, "es preciso conocer lo cómico [...], a fin de nunca hacer ni decir por ignorancia y contra todas las conveniencias cosas risibles". Y Aristóteles (2000a), por su parte, si bien reconoce en la Ética Nicomáquea, 1127b y 1177a, "que en la vida hay también momentos de descanso, en los que es posible la distracción con bromas", subraya y enfatiza que la vida feliz "es la vida conforme a la virtud, y esta vida tiene lugar en el esfuerzo, no en la diversión", que "son mejores las cosas serias que las que provocan risa y son divertidas" y que "la felicidad no está en tales pasatiempos, sino en las actividades conforme a la virtud".

Los pensadores romanos hacen suyo el valor que los filósofos griegos le asignaban a la virtud, que Aristóteles define como "modo de ser elogiable" (2000a, I: 1102b). Para ellos, pensamos por ejemplo en Cicerón (1968, II, p. 236) (pero también en Platón y Aristóteles), la risa proviene del ámbito de lo feo e indecoroso, y nos reímos cuando aquello es señalado decorosamente, es decir, de una manera que sea aceptable para la sociedad. Para los romanos la risa debe contribuir a advertir y corregir una desviación de la norma y de las buenas costumbres, pero debe hacerlo sin vulnerar los principios de gravitas y prudentia concebidos en función de esas normas para delimitar el campo de lo risible.

Se trata, pues, de una risa que surge desde el poder de las estructuras sociales, pero que Plauto suspende en sus comedias para que pueda surgir la otra risa, la risa carnavalesca (Graf, 1999), que es expresión de liberación de las convenciones y restricciones que conforman el molde regulatorio al que debe adaptarse la vida cotidiana en la sociedad. No obstante, para Horacio, quien habla desde las estructuras de poder, aquello es atentatorio contra la urbanitas que le debe poner límites a la licentia, exigencia ésta que lo lleva a criticar a Plauto cuando recuerda que gracias a la urbanitas podemos distinguir entre el chiste ingenioso y la broma grosera y de mal gusto (Horacio, 1967, pp. 270-274). 
Gravitas, auctoritas, prudentia, urbanitas: estimamos que son estos los valores en nombre de los cuales, conjuntamente con la tradición bíblica, se busca controlar sino rechazar la risa-pensamos, por ejemplo, en los versos del Eclesiastés, 7:3: "Más vale llorar que reír", y en Lucas, 6:21: "Bien aventurados los que lloráis ahora, porque reiréis" - conformarán el ideal de la vida cristiana en el medioevo.

Según Hugo Plessner (1970, p. 39), la risa se manifiesta como una irrupción informe e incontrolada del cuerpo emancipada de todo dominio de la voluntad. El hecho que esta repentina relajación, esta liberación de la reprimida condición corpórea del ser humano produzca placer, hace comprensible que en el Medioevo se sospeche de la risa, que se la rechace o se la haga objeto de reglamentación y control. En un mundo que exalta el alma por sobre el cuerpo, que condena el placer físico y presenta la gravitas sacerdotalis como camino hacia la beatitud, no se puede sino desconfiar de la risa que, gracias a su naturaleza corporal y carácter placentero, representa en palabras de Jorge de Burgos, el monje que aparece en la novela El nombre de la rosa de Umberto Eco (1989, p. 467), "la debilidad, la corrupción, la insipidez de nuestra carne".

Jacques Le Goff distingue en la Edad Media tres tendencias en relación a la risa: una primera durante la Alta Edad Media, que busca reprimirla, una segunda durante los siglos XII y XIII que se esfuerza por controlarla mediante la distinción entre una risa aceptable y otra censurable y una tercera tendencia que abarca el final de la Baja Edad Media y que se caracteriza por querer reglamentarla. En la segunda fase -la de la vigilancia e inspecciónse recurre a la diferencia que establece la Biblia Hebraica ${ }^{4}$ entre una risa feliz y desenfrenada que llama sakhaq y otra burlona y denigrante que denomina la'ag, en términos cristianos, entre una risa moral y decorosa y otra zumbona. Los paradigmas para estos dos tipos de risa los ofrece el Nuevo Testamento, para la burlesca, el episodio en que Jesús es objeto de mofas, por ejemplo, en Lucas 23:36: "También los soldados se burlaban de él", y para aquella otra, la risa que surge asociada al amor que es caridad y piedad, entrega incondicional, en anticipación jubilosa del Reino de Dios, la mencionada en Mateo 5:12: "Alegraos y regocijaos, porque vuestra recompensa será grande en los cielos”. Veremos más adelante cómo el Cristianismo reinterpreta la risa festiva, la sakhaq hebrea, que acepta como manifestación espontánea y natural de la fuerza del amor-virtud, pero que rechaza como expresión del placer terrenal que se vive en el amor-pasión.

\footnotetext{
${ }^{4}$ Consúltese, como ejemplo, el Génesis, 18:12 (la’ag) y 26:8 (sakhaq).
} 
Según Bajtin, el hombre medieval "participa al mismo tiempo de dos existencias separadas: la vida oficial y la del carnaval; dos formas de concebir el mundo: una de ellas piadosa y seria y la otra cómica" (1995, p. 90). Por cierto que esta segunda concepción de la realidad se actualiza a través de la fiesta popular, rigurosamente regulada a través del año por la Iglesia y el Estado. La fiesta oficial intenta "consagrar la estabilidad, la inmutabilidad y la perennidad de las reglas que regían el mundo". Por el contrario, las festividades, especialmente las de las ferias y el carnaval, buscan suspender provisionalmente "las relaciones jerárquicas, privilegios, reglas y tabúes" ( $\mathrm{p}$. 15). Rige en estas fiestas el principio de la risa ambivalente, por cuanto es "alegre y llena de alboroto, pero al mismo tiempo burlona y sarcástica, niega y afirma, amortaja y resucita a la vez" (p. 17).

No obstante la represión -violencia, prohibiciones y restricciones- ejercidas por las estructuras de poder en la sociedad feudal, el referente permanente y último de la risa en la Edad Media es la muerte ante la cual bien puede constituirse en una expresión de júbilo por haberla vencido en Jesucristo, risa-ágape, expresión de piedad y desasimiento, fundada en la certeza de la resurrección y la vida eterna. Sin embargo, además de esta risa-sakhaq aceptada en cuanto reinterpretada como manifestación del amor-virtud, existe aquella otra basada en el amor-pasión, risa-sakhaq también ella, pero reglamentada, porque al confundirse con el inagotable fluir, destrucción y creación de formas individuales deviene en una -como diría Schopenhauer- expresión jubilosa y triunfante de la voluntad de vivir. Es la risa que desafía a la muerte y que en cuanto celebración de la vida supera la conciencia de finitud, porque -en términos de Bajtin- "era una expresión de fuerza, de amor, de procreación y fecundidad: estaba vinculada a la abundancia, la comida, la bebida, la inmortalidad terrenal del pueblo, el porvenir, la novedad que abría nuevos caminos" (p. 90). En consecuencia, este último tipo de risa aparece en el mundo medieval -y por cierto que con más fuerza aun en el Renacimiento- como un acto de liberación de la intimidación y el miedo, derivados tanto de las estructuras de poder que pesan sobre los seres humanos como de la gravedad que significa la permanente advertencia de su condición mortal.

Es curioso observar que la risa en su expresión erótica cumple una función parecida en el mundo cultural náhuatl. De hecho leemos en los huehuetlahtolli del Códice Florentino (León-Portilla, 1978, p. 291) -se trata de los consejos que el padre le da a su hija-que "para que no siempre andemos gimiendo, para que no estemos llenos de tristeza, el Señor nuestro nos dio a los hombres la risa, el sueño, los alimentos, nuestra fuerza y nuestra ro- 
bustez, y finalmente el acto sexual, por el cual se hace siembra de gentes. Todo esto embriaga la vida en la tierra, de modo que no se ande siempre gimiendo".

Destacamos y vinculamos la risa y el acto sexual en esta enumeración de bienes que arrebatan y extasían, por cierto que no antojadizamente sino porque también en otras ocasiones se las relaciona. Es así como en los versos de un poeta mexica:

Mi gran jefe, llego: yo vengo a reír.

Soy cara traviesa, flor es mi canción.

(Garibay, 2000c, p. 39)

"vengo a reír" puede significar literalmente lo que la mujer dice, pero de la misma manera que viene dispuesta a hacer el amor. Y esta última significación de la risa la encontramos también en el Canto de las mujeres de Chalco:

Ven a tomarla, ven a tomarla: mi alegría:

oh, mijito, dámete, hijito mío.

Entre alegres gozos estaremos riendo, entraremos en alegría y yo aprenderé.

(Garibay, 2000c, p. 56)

En consecuencia, en esta primera aproximación al sentido de la risa apreciada en la dimensión cotidiana del mundo cultural mexica, debemos retener, por una parte, su tajante oposición a la tristeza y al dolor -"no hay lugar de bienestar en la tierra, no hay alegría, no hay felicidad", habíamos leído en huehuetlatolli antes citado- $y$, por otra, su rol reconfortante cuando, en cercanía con lo que el Medioevo denominaba el loco amor, se asocia al goce y deleite erótico como asimismo con el sexo, la fertilidad y la vida.

En general podemos decir que nos reímos en función de una norma o de un sistema de normas que conforman el orden establecido. Es por eso que distinguimos entre dos formas opuestas de risa:

5 "Ya nihuetzcatihuitz, "yo llego riéndome": el verbo huetzca significa "reír" pero designa también el acto sexual cuando es acompañado del vocablo cihuatl "mujer", de ahí la ambigüedad fundamental de la expresión que implica aquí un sema que establece la isotoía: sexo".

"Xochitl in nociuc, "flor es mi canto". Esta expresión aparentemente muy inocente [...], esconde otro sentido. Xochitl, "la flor", de hecho se ve asociada frecuentemente con el sexo entre los indígenas mexicanos... Si nuestra interpretación de estos dos primeros versos es correcta: "flor (sexo) es mi canto (danza)" da la tonalidad al conjunto del texto. [...] La flor se ajusta entonces a la isotopía sexual sin dejar de ser "flor" como tal" (Johannson, 1991, p. 87 s). 
-una que surge como una práctica de poder para censurar desde el punto de vista de su coherencia y cohesión internos, la vulneración del orden vigente y contribuir de esta manera a su fortalecimiento y perpetuación, y

-otra que brota como un acto de resistencia ante el poder establecido, cuando se lo enfocan en sus contradicciones e incoherencias para develar de esta manera sus inconsistencias y fragilidad.

Umberto Eco sintetiza esta dinámica de la risa en su estudio Elogio de Franticuando anota que "el primer modo de creer [en el orden existente] es no reírse de él” (1988, p. 148). Consecuentemente, cuando la risa surge desde dentro y a partir de esa realidad consagrada, no es sino una manifestación de desprecio y una orgullosa expresión de triunfo sobre aquello que se aparta del orden y las instituciones. No obstante, también es posible reír desde dentro pero sobre ese orden consagrado de las instituciones, porque "sólo frente a la risa la situación mide su fuerza: lo que sale indemne de la risa es válido; lo que se derrumba, debe morir" (1988, p. 149) ${ }^{6}$.

Por cierto que el primer tipo de risa constituye una expresión de superioridad de aquel que se identifica con el orden establecido, mientras que el segundo es una manifestación de independencia por cuanto esta risa supone la capacidad de distanciarse del orden de las instituciones vigentes y sancionadas a perpetuidad. Platón y Aristóteles sospechan de este núcleo anárquico y subversivo presente tanto en la risa festiva como en la del tipo cerebral, razón por la cual la temen y busquen eliminar -o, por lo menos, domesticarla. Es por eso que Aristóteles recomienda en la Ética Nicomáquea respetar el término medio al provocar hilaridad, lo cual logran los ingeniosos que son "los que divierten decorosamente" y los que tienen el tacto de "decir y oír lo que le conviene a un hombre distinguido y libre" (1128a) -tacto y decoro que pertenecen ambos al modo de ser intermedio "y en ello radica precisamente la virtud" (1106b).

Una buena caracterización de la risa que surge desde el orden imperante nos la da Aristóteles en la Retórica cuando afirma que causa placer -y la risa causa placer- decir "cosas inesperadas", algo contrario a la opinión y

\footnotetext{
${ }^{6}$ Encontramos ambos tipos de risa en la novela El nombre de la rosa, de Umberto Eco: la triunfante, cuando Jorge de Burgos ríe mientras engulle la Segunda Parte de la Poética, de Aristóteles: "Y se echó a reír, justo él, Jorge. Era la primera vez que lo oía reír", y la crítica que resuena a través de todo el texto en oposición y pugna con la gravedad de un orden sancionado por una vez y para siempre, por cuanto "la tarea del que ama a los hombres consiste que éstos se rían de la verdad, lograr que la verdad ría, porque la única verdad consiste en aprender a liberarnos de la insana pasión por la verdad" (1989, pp. 473 y 484).
} 
no conforme [...] con el parecer que se tenía antes" (1412a). Consecuentemente, lo risible es aquello que se aparta de la norma y, por eso, como anota en la Poética, "un defecto, una fealdad" (1449a). Es la "interminable risa de los dioses afortunados" (Homero, Odisea VIII, p. 326) ante el espectáculo que ofrecen Afrodita y Ares, cuando yacen atrapados en las redes de Hefesto, el marido engañado y ofendido, y que la Biblia Hebraica denomina la'ag, risa burlona que aparece, por ejemplo, cuando Sara, entonces nonagenaria, se mofa de Yahveh cuando éste le anuncia su próximo embarazo: "Ahora que estoy pasada, ¿sentiré el placer, y además con mi marido viejo?” (Génesis 18:12). Sara asume el punto de vista de la naturaleza y desde las leyes que en ella rigen se ríe de Dios.

No obstante, en ocasiones es Dios quien se ríe de los seres humanos, por ejemplo, en el Salmo 2:1 y 4:

¿Por qué se agitan las naciones

y los pueblos mascullan planes vanos?

El que se sienta en los cielos se ríe,

Yahveh se burla de ellos.

-risa desde el poder, irónica y zumbona, que también encontramos en el Libro de Job 5:22-23, pero entonces con una notación diferente, definitivamente inquietante y enigmática:

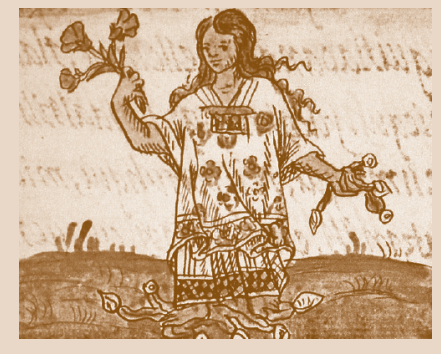

Pero todo da igual, y por eso digo:

Él extermina al intachable y al malvado, sí: un azote acarrea la muerte de improviso, Él se ríe de la angustia de los inocentes.

Y otra vez llama la atención que en la cultura náhuatl de Mesoamérica encontremos esa misma risa como, por ejemplo, en el Códice Florentino (León-Portilla 1979, pp. 199 ss.), donde leemos:

Nuestro Señor, el Dueño del Cerca y del Junto, piensa lo que quiere, determina, se divierte.

[...]

En el centro de la palma de su mano nos tiene colocados, nos está moviendo a su antojo.

[...]

Le somos objeto de diversión: de nosotros se ríe. 
Pero el dios que se ríe de los seres humanos, el Dueño del Cerca y del Junto, el Dador de la Vida, Tezcatlipoca ${ }^{7}$ no sólo goza de la desazón, muerte y desolación de los seres humanos, sino que de la misma manera celebra la creación, el crecimiento y la vida. Su risa es, en consecuencia, ambigua, tanto destructiva como fundacional:

¡Ah, el Dador de la Vida de nosotros se mofa: sólo un sueño perseguimos, amigos.

Aun dolientes gocémonos en la primavera, en medio de colores nos hace vivir El que da la Vida.

(Garibay 2000b, p. 125)

La risa -goce y deleite- surge en el ámbito humano como resonancia y en consonancia con la risa creadora del dios. En ella no sólo vibra la hermosura de la naturaleza:

Nos ataviamos, nos enriquecemos con flores, con cantos:

ésas son las flores de la primavera:

¡con ellas nos adornamos aquí en la tierra!

(Garibay 2000a, p. 51)

y de la creación artística:

Dentro de ti vive, dentro de ti escribe, crea, el Autor de la vida.

(Garibay, 2000a, p. 83)

Variada pintura es mi corazón

es mi canto:

vengo a dar placer, vengo a recrear al que da la vida, aquí sobre la florida estera.

(Garibay, 2000a, p. 21)

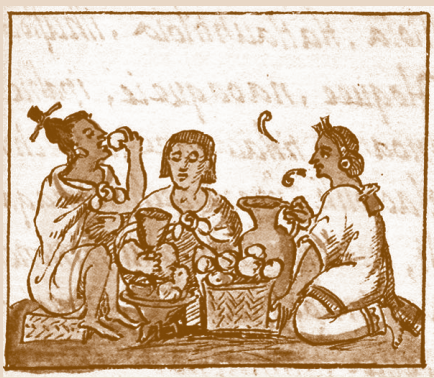


Te vengo a dar deleite, vengo a acabar con tu tristeza.

$[\ldots]$

Soy cantor, vengo a deleitar, vengo hacer reír al dios.

(Garibay, 2000b, p. 17)

La risa se convierte en metáfora de la poesía, poesía de inspiración divina destinada a consolar a los hombres y a complacer al dios. Obviamente, esta risa que deviene de la dimensión creativa opuesta a la dimensión destructiva de Tezcatlipoca, libera y exime a quien participa de ella -al igual que la risa cuando significa deleite sexual- transitoriamente, de las amarguras, pesares y pesadumbres, de las angustias de la existencia.

Estamos ante la risa de Tezcatlipoca, risa ambigua, destructiva y creadora, que también resuena en la risa de los seres humanos pero que ellos buscan controlar en su efecto devastador. Veamos algunos ejemplos:

-La risa burlona que humilla, risa que surge como expresión de independencia ante las estructuras y prácticas de poder, sólo se permite en el mundo mexica-pensamos que en atención a su poder disolvente, desolador-como medio de provocación bélica. $\mathrm{Al}$ respecto recuérdese tan sólo el episodio que lleva a la guerra entre Tenochtitlán y Tlatelolco, porque las mujeres "mostraban sus posaderas con gesto despreciativo a los encolerizados visitantes tenochcas" (Vaillant, 1960, p. 85). Pero en la vida cotidiana se prohíbe la mofa, por ejemplo, cuando se trata de personas que sufren algún impedimento o invalidez: "Y no te rías" leemos en los discursos, los huehuetlahtolli, destinados a la educación de los jóvenes, "no te burles, no hagas bromas (...) de aquel en quien la enfermedad está, o de aquel que sufre con los errores, o de quien frente a ti incurrió en faltas, de quien las cometió. [...] Sólo así, con ello, serás discreto" (León Portilla, 1993, p. 59).

Ciertamente que en este caso se trata de la risa que brota desde la norma y el orden como manifestación de desprecio y expresión de triunfo de la normalidad sobre todo aquello que sea, en términos de Aristóteles, un "defecto o fealdad" (Poética, 1449a) o "contrario a la opinión común" (Retórica, 1412a). En oposición a ella se postula el principio de la moderación, en última instancia, el llamado a humanizarse en función de los ideales de mesura y moderación: "si te burlas de la gente, así no saldrás humano", leemos un poco más adelante en el texto citado, apelación de llegar a ser 
humano humanizándose en el ejercicio del respeto, práctica de la compostura y la consideración.

-Y otro tanto sucede con la risa asociada al deleite sexual, no obstante su capacidad de embriagar y, en consecuencia, de eximir a los seres humanos de los dolores, las angustias y penurias de la vida. Porque, como leemos en otro de los huehuetlahtolli, en los consejos que le da la madre a su hija, "no irás jadeando, no irás riéndote", "si [un hombre] se burlara de ti, no le rías [...], no irás viendo de reojo [...] para que lo provoques, para que no excites al depravado", (León-Portilla y Silva Galeana, 1993, pp. 92 y 95 s.). Pensamos que esta prohibición se explica por cuanto a la ahuianime se la caracteriza en el Código Matricense como "la alegradora [que] con su cuerpo da placer $[\ldots]$ vuelve el ojo arqueando, se ríe, ándase riendo" (LeónPortilla, 1998, p. 70).

Claramente la cultura náhuatl reconoce el aspecto placentero, gozoso del amor erótico, pero de la misma manera teme su fuerza transgresora, anárquica, contraria a los códigos morales, las normas y las instituciones. Es por eso que busca domesticar su fuerza, someterla a reglas, imponer sobre ella el principio del decoro, el recato y de la honestidad, porque "sólo así, en el medio, está lo que corresponde a la comunidad, la honra" (LeónPortilla y Silva Galeana, 1993, p. 92). Otra vez, al igual que en el caso de la risa zumbona, surge ante la risa asociada al placer erótico el propósito de controlar su carácter disolvente, conturbador.

Los nahuas se esfuerzan por regular y dominar a la risa, porque identifican en ella el eco de la risa de Tezcatlipoca y saben de su poder destructivo para los seres humanos y para las instituciones en que se fundamenta la sociedad. Pero ellos comprenden también que esa fuerza devastadora es la consecuencia del poder creador que palpita y pulsa a través de la risa y que en su exuberancia destruye las formas y estructuras de su creación. Tezcatlipoca se ríe del empeño que los seres humanos ponen en controlar esa fuerza destructora que opera en el poder creador, porque es esa misma fuerza la que deviene en individuos e instituciones, pero que una y otra vez disuelve su obra llevado por su ímpetu creador -frenesí que siempre tiende a proyectarse más allá de lo alcanzado. Los humanos se aferran a sus creaciones en un esfuerzo que causa la hilaridad del dios?.

Recapitulemos. Estos apuntes sobre amor y risa nos permiten adelantar las siguientes conclusiones, por cierto que parciales y fragmentarias:

\footnotetext{
${ }^{9}$ Consúltese al respecto Planchart Licea, 2000, p. 43.
} 
-En general hemos podido distinguir dos tipos de risa, una festiva y otra altanera, ambas propias del género humano, radicadas en las sociedades e insertos en el devenir.

-No obstante, la separación entre las variadas manifestaciones de la risa vital y festiva y la del tipo zumbona en sus diversas formas y variedades, no es tan tajante como pareciera, y más bien parece tratarse de un problema de prevalencia de una por sobre la otra, según el momento y la ocasión.

-El origen de la risa debe buscarse en la sorpresiva percepción de una incongruencia cuyos términos cambian conforme a la situación y la circunstancia, en el contexto del respectivo momento histórico, cultural y social.

-La risa vital y festiva aparece íntimamente relacionada en una de sus expresiones con el amor-pasión, "el loco amor del mundo", en expresión del Arcipreste de Hita (1967), por lo que a ambos se los busca confinar en el espacio privado de la sociedad.

-En las culturas hebrea, clásica y mexica, la risa, aunque no prohibida, se la desea controlada, y siempre aparece desvalorizada cuando se relaciona la risa con la gravedad -acaso porque en ella vibra un incontrolable impulso de vitalidad.

-En cuanto "celebración de la vida" ${ }^{10}$, la risa-pasión es profundamente transgresora, destructora de todo límite y creadora de un impulso vital libre e infinito.

Ayer te vi reír

y los barrotes se quebraron

el sol entró en mis ojos

y me recorrió entera

La primavera se paseó por los pasillos

rompiendo puertas

y en tus carcajadas

los muros se hicieron polvo

y los candados se cambiaron por campanas

y cantaron

el nacimiento de la libertad

sobre los escombros carcelarios.

(Herrera, 1988, p. 14)

\footnotetext{
${ }^{10}$ Esta expresión sintetiza un aspecto de la risa según lo estudiado en Salinas (1996).
} 


\section{REFERENCIAS}

Aristófanes (1991). Lisístrata, en: Las once comedias. México: Ed. Porrúa. Aristóteles (1974). Poética. Madrid: Ed. Gredos. . (1990). Retórica. Madrid: Ed. Gredos - (2000a). Ética Nicomáquea, en: Ética de Nicomáquea. Ética Eudemia. Madrid: Ed. Gredos. . (2000b). Partes de los animales, en: Partes de los animales. Marcha de los animales. Movimiento de los animales. Madrid: Ed. Gredos.

Bajtin, M. (1995). La cultura popular en la edad Media y en el Renacimiento. Madrid: Alianza Editorial.

Bendezú Aybar, E. ( $\left.{ }^{2} 1992\right)$. Literatura quechua. Caracas: Biblioteca Ayacucho.

Berger, P. L. (1998). Erlösendes Lachen. Das Komische in der menschlichen Erfahrung. Berlin - New York: Walter de Gruyter Verlag.

Bergson, H. (1943). La risa. Buenos Aires: Ed. Losada.

Biblia Hebraica (1997). Stuttgart: Deutsche Bibelgesellschaft.

Biblia de Jerusalén (2009). Bilbao, España: Editorial Desclée De Brouwer.

Borges, J. L. (1996). Enjoyment of laughter, de Max Eastman, en: Obras completas IV. Barcelona: Emecé Editores, p. 329 s.

Cicerón (1968). De oratore, München: Goldmann Verlag.

De la Garza, M. ('1992). Literatura maya. Caracas: Biblioteca Ayacucho.

Eco, U. (1988). “Elogio de Franti”, en: Diario mínimo. Barcelona: Ed. Península, p. 137 ss.

. (1989). El nombre de la rosa. Barcelona: Ed. Lumen.

Fietz, L. (1995). Möglichkeiten und Grenzen einer Semiotik des Lachens, en: Fietz et al., Semiotik, Rhetorik und Soziologie des Lachens. Vergleichende Studien zum Funktionswandel des Lachens vom Mittelalter zur Gegenwart. Tübingen: Max Niemeyer Verlag, p. 7 ss.

Freud, S. (1967). El chiste y su relación con lo inconsciente en: Obras completas I. Madrid: Ed. Biblioteca Nueva, p. 825 ss.

Garibay, Á. M. (2000a). Poesía náhuatl I. México: UNAM. . (2000b). Poesía náhuatl II. México: UNAM. . (2000c). Poesía náhuatl III. México: UNAM.

Graf, F. (1999). "Cicero, Plautus und das römische Lachen", en: Bremmer, J. - Rodenburg, H. (Hrsg), Kulturgeschichte des Humors. Von der Antike bis heute. Wissenschaftliche Buchgeselschaft, p. 32 ss.

Herrera, V. (1988). Poesía prisionera. Escritura de cinco mujeres encarceladas. Santiago: Ediciones Literatura Alternativa.

Hegel, G. W. F. (1970). Vorlesungen über die Ästhetik III. Frankfurt am main: Suhrkamp Verlag.

Heyden, D. (1989). “Tezcatlipoca en el mundo náhuatl”, en: Estudios de cultura náhuatl, 19, (México), UNAM: Instituto de Investigaciones Históricas.

Homero (1959). Ilíada. México: Ed. Porrúa. . (1979). Ilias / Odyssee. München, dtv. 
Horacio (1967). "De arte poetica“, en: Werke. München: Ernst Heimeran Verlag, p. 230 ss.

Johannson, P. (1991). “El cuecuechcuicatl: canto travieso de los aztecas", en: Estudios de cultura náhuatl, 21, UNAM: Instituto de Investigaciones Históricas, pp. 83-97.

Kant, I. (1966). Kritik der Urteilskraft. Stuttgart: Reclam.

Le Goff, J. (1999). "Le rire dans la societé médiévale", en: Le Autre Môyen Âge. Paris: Éditions Gallimard, p. 1341 ss.

León-Portilla, M. (1978). Literatura del México Antiguo. Caracas, Biblioteca Ayacucho.

. (1979). La filosofía náhuatl. México: UNAM.

(1993). Huehuehtlahtolli. Testimonios de la antigua palabra. México, FCE.

(1998). Quince poetas del mundo náhuatl. México: Ed. Diana.

Neruda, P. (1968). Los versos del capitán en: Obras Completas I. Bs. As.: Ed. Losada, p. 941 ss.

Planchart Licea, E. (2000). Lo sagrado en el arte: la risa en Mesoamérica. Xalapa, Veracruz, México: Universidad Veracruzana.

Platón (1969). Filebo o del placer y Leyes, en: Obras Completas. Madrid: Ed. Aguilar, p. 1218 ss. y p. 1274 ss., respectivamente.

Plessner, H. (1970). Lachen und Weinen, en: Philosophische Anthropologie. Frankfurt am Main: S. Fischer Verlag, p. 19 ss.

Ritter, J. (1974). Über das Lachen, en: Subjektivität. Frankfurt am main: Suhrkamp Verlag, p. 62 ss.

Ruiz, J. el Arcipreste de Hita (1967). Intellectum tibi dabo, en: Libro de buen amor. Madrid: Ed. Gredos.

Salinas, M. (1996). Risa y cultura en Chile. Santiago: Universidad ARCIS, Documentos de trabajo e informes.

Schopenhauer, A. (1977). Die Welt als Wille und Vorstellung I: 1. Zürich: Diogenes.

Soggin, J. A. (1997). Das Buch Genesis. Darmstadt: Wissenschaftliche Buchgesellschaft.

Vaillant, G. C. (1960). La civilización azteca. México: FCE. 